\title{
Ribosomal RNA processing in Candida albicans
}

\author{
MICHAEL L. PENDRAK ${ }^{1}$ and DAVID D. ROBERTS
}

Laboratory of Pathology, Center for Cancer Research, National Cancer Institute, National Institutes of Health, Bethesda, Maryland 20892, USA

\begin{abstract}
Ribosome assembly begins with conversion of a polycistronic precursor into $185,5.8 S$, and $25 S$ rRNAs. In the ascomycete fungus Candida albicans, rRNA transcription starts $604 \mathrm{nt}$ upstream of the $18 \mathrm{~S}$ rRNA junction (site A1). One major internal processing site in the $5^{\prime}$ external transcribed spacer (A0) occurs $108 \mathrm{nt}$ from site A1. The A0-A1 fragment persists as a stable species during log phase growth and can be used to assess proliferation rates. Separation of the small and large subunit prerRNAs occurs at sites A2 and A3 in internal transcribed spacer-1 Saccharomyces cerevisiae pre-rRNA. However, the 5' end of the 5.8S rRNA is represented by only a $5.8 \mathrm{~S}(\mathrm{~S})$ form, and a 7S rRNA precursor of the 5.8S rRNA extends into internal transcribed spacer 1 to site A2, which differs from $S$. cerevisiae. External transcribed spacer 1 and internal transcribed spacers 1 and 2 show remarkable structural similarity with $S$. cerevisiae despite low sequence identity. Maturation of $C$. albicans rRNA resembles other eukaryotes in that processing can occur cotranscriptionally or post-transcriptionally. During rapid proliferation, U3 snoRNA-dependent processing occurs before large and small subunit rRNA separation, consistent with cotranscriptional processing. As cells pass the diauxic transition, the $18 \mathrm{~S}$ pre-rRNA accumulates into stationary phase as a $23 \mathrm{~S}$ species, possessing an intact 5' external transcribed spacer extending to site A3. Nutrient addition to starved cells results in the disappearance of the 235 rRNA, indicating a potential role in normal physiology. Therefore, $C$. albicans reveals new mechanisms that regulate post- versus cotranscriptional rRNA processing.
\end{abstract}

Keywords: $23 S$ pre-rRNA; rRNA processing; U3 snoRNA; Candida albicans

\section{INTRODUCTION}

Ribosome assembly is a complex biological process involving numerous structural and accessory proteins as well as four species of ribosomal RNA (rRNA) (Venema and Tollervey 1999). Three of these rRNA species are processed from a single RNA polymerase I-derived tricistronic transcript (Fig. 1A). A series of endonucleoytic and exonucleolytic events via specific rRNA processing complexes (processomes) in the nucleolus form the mature rRNA species (Granneman and Baserga 2004). This process had been visualized by electron microscopy (Osheim et al. 2004) and is cotranscriptional in rapidly proliferating cells (Osheim et al. 2004; Kos and Tollervey 2009). These initial cleavage events progress sequentially $5^{\prime}$ to $3^{\prime}$ beginning with endonucleolytic processing steps at sites A0, $\mathrm{A} 1$, and $\mathrm{A} 2$ and are dependent upon the box C/D small nucleolar RNA (snoRNA) U3 (Fig. 1A). This process results in two major precursors that are processed to yield the small

\footnotetext{
${ }^{1}$ Corresponding author.

E-mail mpendrak@helix.nih.gov.

Article published online ahead of print. Article and publication date are at http://www.rnajournal.org/cgi/doi/10.1261/rna.028050.111.
}

ribosomal subunit (SSU, 18S) and the large ribosomal subunit (LSU; 5.8S and 25S) (Fig. 1B, Model 1). U3 snoRNA disruption leads to loss of the $5^{\prime}$ terminal knobs (SSU processome) of pre-rRNA (Dragon et al. 2002), and the LSU and SSU processomes serve to organize the constituents of the large and small ribosomal subunits, respectively (Granneman and Baserga 2004). Under certain circumstances, post-transcriptional processing has also been shown to occur. A mild heat shock of Saccharomyces cerevisiae cells is sufficient to change the processing order to post-transcriptional where cleavage in ITS1 results in SSU-LSU separation prior to the U3 snoRNA-dependent processing steps (Fig. 1B, Model 2; Osheim et al. 2004). Whether originating from a 27S-A2 or a 27S-A3 precursor, LSU rRNA maturation is independent of SSU rRNA maturation, consistent with the identification of LSU and SSU processomes (Granneman and Baserga 2004).

The generation of either a 27S-A2 or 27S-A3 LSU precursor is resolved in one of two distinct steps in S. cerevisiae. In the majority of cases, the $27 \mathrm{~S}-\mathrm{A} 2$ precursor is cleaved at site A3 by the endonuclease activity of the RNase MRP1 complex. Subsequent $5^{\prime}-3^{\prime}$ exonuclease activity then forms the $5^{\prime}$ end of the 5.8S rRNA species at site B1 (Fig. 1C). In a minority of cases, an unknown endonuclease cleaves the 27S rRNA 
A.

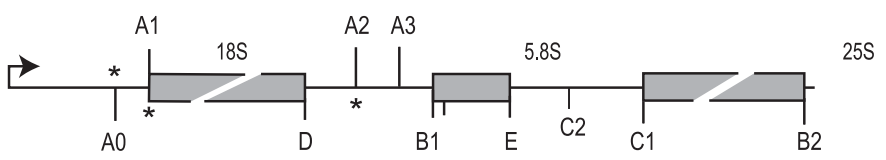

B.

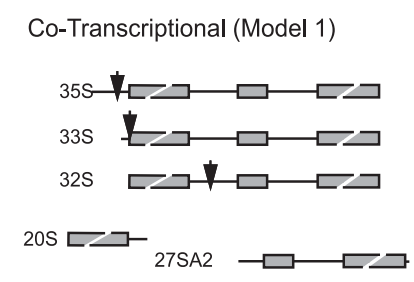

Post-Transcriptional (Model 2)

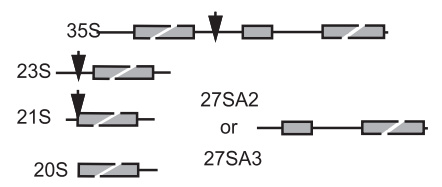

C.

D.
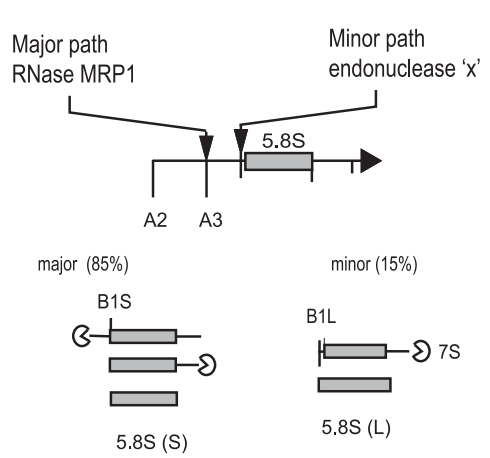

\begin{tabular}{lcccccc} 
& $5^{\prime}$ ETS & $18 S$ & ITS-1 & $5.8 S$ & ITS-2 & $25 S$ \\
\cline { 2 - 7 } C. albicans & $604^{*}$ & 1787 & 138 & 158 & 155 & 3361 \\
S. cerevisiae & 700 & 1800 & 361 & 158 & 232 & 3396 \\
\cline { 2 - 7 } Identity (\%) & 50.3 & 94 & 27.2 & 95 & 43.5 & 90.2 \\
* Length in nucleotides & & & & &
\end{tabular}

FIGURE 1. An overview of ribosomal RNA processing in Eukaryotes. (A) Structure of the RNA polymerase I transcript depicting processing intermediates and location of processing sites. The sequential steps are performed by a combination of exo- and endonucleases and are generally followed in the order listed from left to right after the primary processing step in the $3^{\prime}$ ETS (data not shown). $\left(^{*}\right)$ U3 snoRNA-dependent cleavage sites. $(B)$ Two models of pre-rRNA processing. Model 1 depicts cotranscriptional processing, where 5' ETS depletion occurs before SSU and LSU separation occur. The $20 \mathrm{~S}$ SSU precursor is processed cytoplasmically. Post-transcriptional processing (Model 2) results in a distinct set of $18 \mathrm{~S}$ pre-rRNA intermediates, and the identity of the $5^{\prime}$ end of the LSU RNA may differ. In both models, processing in ITS1 defines the fate of the $18 \mathrm{~S}$ and 5.8S-25S rRNA intermediates to the SSU and the LSU, respectively. Arrows indicate endonuclease processing sites. $(C)$ Processing of the 27SA2 intermediate can follow two pathways: (1) a major pathway involving RNaseMRP1 cleavage at site A3 followed by exonuclease trimming to the $5^{\prime}$ end of the $5.8 \mathrm{~S}$, and (2) a minor pathway occurring by endonuclease digestion at site $\mathrm{B} 1 \mathrm{~L}$. This internal cleavage generates a $5.8 \mathrm{~S} \mathrm{rRNA}$ species that is $6 \mathrm{nt}$ longer than that generated by the major pathway. L (long), S (short) (Venema and Tollervey 1999; Fromont-Racine et al. 2003). Crescent-shaped characters indicate start points for exonuclease digestion. $(D)$ A comparison of the nucleotide lengths of the rRNAs and spacers of $S$. cerevisiae and C. albicans. The lengths listed were generated from the RDN1 loci listed in the Saccharomyces (Cherry et al. 2002) and Candida (Arnaud et al. 2007) genome databases. Sequence identity was determined using the NeedlemanWunsch algorithm (Needleman and Wunsch 1970).

precursor at a site $6 \mathrm{nt} 5^{\prime}$ of site B1 (termed B1L) (Fig. 1C). In both of these instances, an unidentified endonuclease cleaves site C2 in ITS2 to separate the 5.8S and 25S rRNA precursors. The final trimming occurs through a combination of $5^{\prime}-3^{\prime}$ and $3^{\prime}-5^{\prime}$ exonuclease action (Fig. 1C).

We are investigating pre-rRNA processing in the human commensal fungus Candida albicans. Overall, the polycistronic structure of the C. albicans rDNA locus resembles that of other eukaryotes (Fig. 1) with some significant differences in the length and composition of the external and internal spacer regions (Fig. 1D). We mapped the processing sites of the primary rRNA transcript and identified the rRNA maturation pathway in this organism. Cotranscriptional and posttranscriptional rRNA-processing modes could both be distinguished. Interestingly, a pre-18S rRNA that retained the $5^{\prime}$ ETS with an endpoint at site A3 (23S pre-rRNA) persists and accumulates to high levels after the diauxic transition, indicating that it occurs as a normal part of the organism's physiology. This $23 \mathrm{~S}$ rRNA species is the result of processing at site A3, indicating a post-transcriptional processing mechanism, and is apparently functional since it disappears at high levels within the first hour after transfer of cells into new medium. The metabolic control of these two rRNA processing mechanisms may provide insights into the regulation and potential functions of these two mechanisms.

\section{RESULTS}

\section{The 5' ETS region of the $C$. albicans RNA polymerase I transcript}

The RDN1 (ribosomal DNA, rDNA) locus of $C$. albicans contains multiple copies of tandemly arrayed rRNA-encoding genes located on chromosome $\mathrm{R}$ (Wickes et al. 1991; Rustchenko et al. 1993; Jones et al. 2004). The length of each copy (11.6-12.5 $\mathrm{kb})$ and the copy number (21-176) depend upon the strain and the growth conditions (Wickes et al. 1991; Rustchenko et al. 1993). Our goal was to define the processing sites in the tricistronic RNA polymerase I rRNA transcript guided by sequence information in the Candida Genome Database (Arnaud et al. 2007). The overall identity of the three mature rRNA sequences to $S$. cerevisiae and other organisms is very high and is typical considering the strong evolutionary pressures that have governed ribosome development. On the other hand, the intergenic regions show extensive sequence divergence (Venema and Tollervey 1999) and are significantly shorter in C. albicans (Fig. 1D).

We used primer extension analysis to map the $5^{\prime}$ end of the $C$. albicans rRNA primary transcript in the $5^{\prime}$ external transcribed spacer (5' ETS). A nucleotide comparison with the $5^{\prime}$ ETS of $S$. cerevisiae indicated that the transcription start sequence ATGCGAAAGCAGAAA was colinear with the C. albicans $5^{\prime}$ ETS and positioned $604 \mathrm{nt}$ upstream of the predicted $18 \mathrm{~S}$ rRNA junction. Using this information as a guide, extension of RT primers 118 and 203 nt from this site (Fig. 2D, RT primers 1 and 2) resulted in identical products that terminated at the adenine that was predicted by 
sequence homology (Fig. 2A). We also confirmed the $18 \mathrm{~S}$ junction using an RT primer within the $18 \mathrm{~S}$ rRNA (Fig. 2D, RT primer 4). This site was exactly $604 \mathrm{nt}$ from the transcription start site at the second of a uridine pair, which corresponds to the mapped position of the $S$. cerevisiae sequence (Fig. 2B). Therefore, the C. albicans transcription start site is located $604 \mathrm{nt}$ from the $18 \mathrm{~S}$ rRNA junction.

Internal $5^{\prime}$ ETS processing sites were identified by reverse transcription of a labeled primer located $2 \mathrm{nt} 5^{\prime}$ of the $18 \mathrm{~S}$ rRNA junction (Fig. 2D, RT primer 3). A major stop was identified at a guanine $497 \mathrm{nt}$ from the transcription start site along with two minor sites at 519 and 523 nt (Fig. 2C). These results are consistent with the placement of an A0 site 108 nt upstream of the 18S rRNA junction (Fig. 2D). A processing site would be expected in this region since the A0 site in S. cerevisiae is located $90 \mathrm{nt}$ upstream of the $18 \mathrm{~S}$ junction, and other eukaryotes follow a similar pattern (Venema et al. 1995; Venema and Tollervey 1999; Granneman and Baserga 2004). In S. cerevisiae, processing at this site is dependent upon the snoRNA U3, and base pairing with a region just downstream from the $\mathrm{U} 3$ snoRNA " $\mathrm{A}$ " box is required for this activity (Beltrame and Tollervey 1995). We identified an extended singlestranded region in the predicted 5' ETS folded structure that is complementary to the $C$. albicans U3 snoRNA sequence (Fig. 3, inset). The $5^{\prime}$ ETS pairing site occurs at a position in the snoU3 genes identical to that of S. cerevisiae (Fig. 3, inset) and is positioned in a similar unpaired region in hairpin VII (Fig. 3). Interestingly, we also identified a minor RT stop at position 413, which is exactly at the end of this region (Fig. 2C, U3 box).

Overall, the predicted folded structure of the C. albicans $5^{\prime}$ ETS is very similar to that of S. cerevisiae (Fig. 3; Yeh and Lee 1992). The 10 stem-loop structures of the $S$. cerevisiae model are very similar to that of the C. albicans model (cf. Fig. 3 and Yeh and Lee 1992). The $\sim 100$-nt difference between the two species is accommodated by the absence of one stem-loop structure in the C. albicans model that would occur between structures VIII and IX of Figure 3. Processing site A0 occurs in a minor loop located between these two structures, and site A0 in the $S$. cerevisiae model occurs in a similar position between the predicted

D.

E. stem-loops IX and X (Yeh and Lee 1992). The region predicted for the U3 snoRNA pairing occurs in an extended single-stranded region and is also similar to the position of the predicted S. cerevisiae structure (Fig. 3; Yeh and Lee 1992).

\section{Production of a small stable RNA from the 5' ETS during log-phase growth}

To examine RNA products in the 5' ETS more closely, we first used Northern hybridization analysis of small RNAs
A.

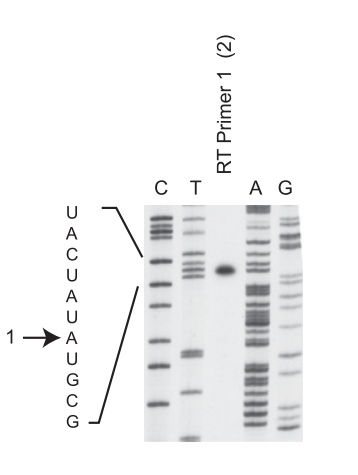

B.

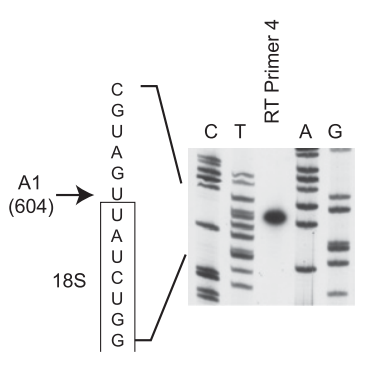

c.

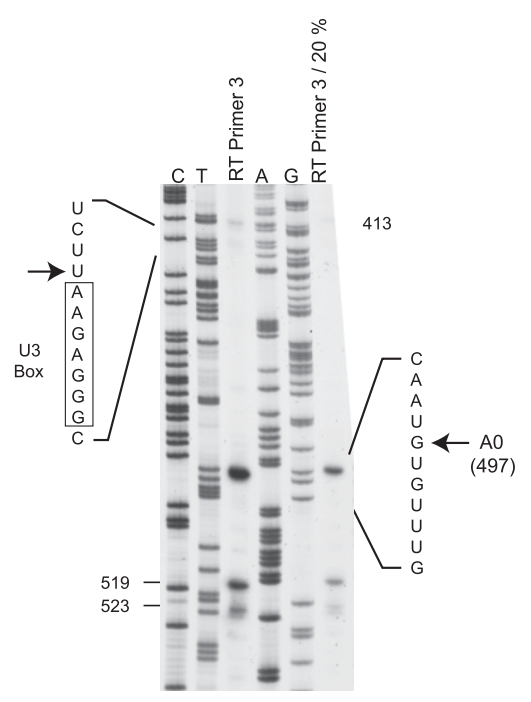

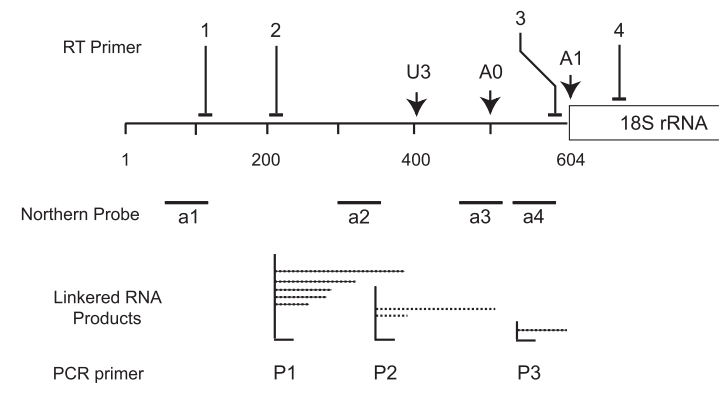

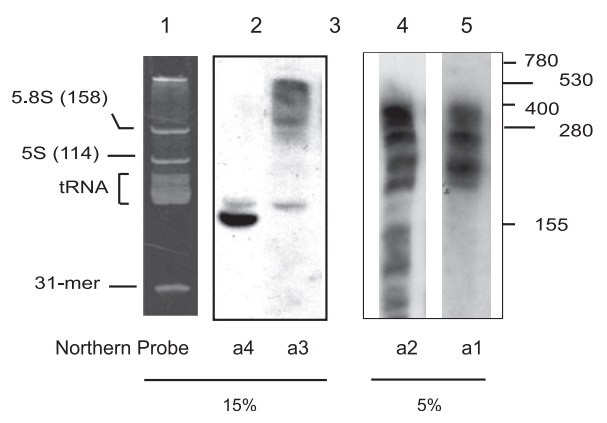

FIGURE 2. (Legend on next page) 
that had been purified from total RNA using a commercial kit for microRNA isolation. These small RNAs were separated by denaturing PAGE in either $15 \%$ or $5 \%$ gels (see Fig. $2 \mathrm{E}$, lane 1 ), and electro-blotted onto a positively charged membrane for Northern analysis. The fractionated small RNA population was also cloned by adding linkers using RNA ligase, reverse transcription, and PCR amplification by one of three primers to selectively amplify RNA products from the 5' ETS region (see Fig. 2D for PCR primers).

Northern analysis using a probe from the 5' ETS region adjacent to the $18 \mathrm{~S}$ rRNA junction identified a small and stable RNA from the A0-A1 region as well as a minor band migrating slightly slower (Fig. 2E, lane 2) (see Fig. 2D for probe locations). Sequence analysis of linkered RNA yielded only a single product when primer P3 was used for PCR amplification. The $3^{\prime}$ end was identified as site A1 (Fig. 2D, primer P3; the location of all cloned fragments are indicated in Fig. 3). A Northern probe located just upstream of the A0 site (probe a3) hybridized to the minor species migrating just above the A0-A1 fragment (Fig. 2E, cf. lanes 2 and 3). This suggested that the A0 site may not always be located at the precise nucleotide determined by primer extension. Interestingly, an area spanning the region 75 to $175 \mathrm{nt} 5^{\prime}$ of the A0A1 fragment was striking for its lack of hybridization to probe a3 (Fig. 2E, lane 3). Sequencing of linkered RNA using PCR primer P2 resulted in the identification of only two species of RNA with $3^{\prime}$ ends in this region. The shorter RNA ended near the predicted snoU3 pairing site, and the other extended to site A0 (Fig. 2D). RNA 3' ends identified by the use of PCR primer P1 did not extend past the U3 snoRNA site (Fig. 2D). Together, these data indicated that the region in the $5^{\prime}$ ETS RNA between A0 and the snoU3 pairing site is rapidly degraded in a $3^{\prime}-5^{\prime}$ direction. In support of this, probe "al" was found to hybridize to only long RNA species that abruptly ended near the 175-nt region (Fig. 2E, lane 5).
Also, probe "a2" showed a lack of hybridization in a large region near the 155-nt RNA marker, but still hybridized to the longer RNAs (Fig. 2E, lane 4).

These results demonstrate that the region between the snoU3 pairing and A0 sites defines a sharp boundary between two relatively stable ends of the $5^{\prime}$ ETS region. The A0-A1 fragment is particularly stable in rapidly proliferating cells and is a candidate marker for assessing cell proliferation rates (see below).

\section{ITS1 rRNA processing}

Processing in the ITS1 region is essential for proper rRNA maturation. This region possesses one of three U3 snoRNAdependent cleavage sites (site A2), and processing at this site is essential for separation of the SSU and LSU rRNA components in S. cerevisiae (see Fig. 1A). ITS1 is $223 \mathrm{nt}$ shorter in C. albicans than in S. cerevisiae and this difference is largely due to lack of an extended 200-nt loop between sites D and A2 (Fig. 4C). The sequences surrounding the potential A2 and A3 processing sites are similar in both species, and the overall predicted folding of the two ITS1 region RNAs are similar (Fig. 4C).

We used primer extension analysis to map the processing sites in the $C$. albicans ITS1. A single primary extension product was detected using a primer located just upstream of the 5.8S rRNA junction. This product corresponded to the A2 processing site as predicted by the model and occurred at a site AACCA that varied from the evolutionarily conserved site ACAC in S. cerevisiae (Fig. 4A; Allmang et al. 1996). This procedure did not identify a potential A3 site in ITS1, so we repeated the analysis using RNA isolated from cells in the stationary growth phase, $1 \mathrm{~h}$ after transfer to new medium, and in exponential growth (Fig. 4B, lanes 1, 2, 3, respectively). We could only identify a minor RT stop near a region predicted for site $\mathrm{A} 3$, but this occurred at the base of stem-loop 31 (Fig. 4B, lane 2). However, this RT stop was not present when reverse transcription was carried out at $65^{\circ} \mathrm{C}$ (data not shown). Therefore, either C. albicans lacks an A3 site, or the abundance of RNA molecules with this $5^{\prime}$ endpoint is below the detection limits of this procedure.

a sequencing ladder was generated using the same primer. One major RT stop occurs $604 \mathrm{nt}$ from the transcription start site and identifies the $5^{\prime}$ end of the 18S rRNA (Site A1). (C) Identification of an A0 internal processing site. Primer extension analysis using primer RR120 (Primer 3) was electrophoresed with a sequencing ladder generated using the same primer. A major RT stop occurred at nucleotide 497 and minor sites are indicated. The site at position 413 coincides with the end of the proposed snoU3-pairing region. (D) Map of the 5' External Transcribed Spacer $\left(5^{\prime}\right.$ ETS) showing primers and probes in the experiments depicted here. The numbers are in nucleotides with 1 indicating the transcription start site. The length of linkered RNA products are indicated as dotted lines below the figure. Indicated lengths are in nucleotides. U3; predicted complementary U3 snoRNA pairing site; A0, internal cleavage site; Al, $18 \mathrm{~S}$ rRNA $5^{\prime}$ end. (E) Northern analysis of RNA products in the $5^{\prime}$ ETS region. Total RNA enriched for species $<500 \mathrm{nt}$ (mirVana kit, Ambion) and electrophoresed through denaturing acrylamide gels (\% indicated). (Lane 1) EtBr-stained gel; (lanes 2-5) Northern blots hybridized with probes a4, a3, a2, and a1, respectively. Sizes in nucleotides are indicated.

\section{An 185 rRNA precursor accumulates as a high molecular weight intermediate in post-diauxic shift cells}

In the cotranscriptional model for separation of the SSU and LSU rRNAs, processing at sites $\mathrm{A} 0$ and $\mathrm{A} 1$ occurs before the separating cleavage at site A2. Thus, separation of the LSU and SSU 


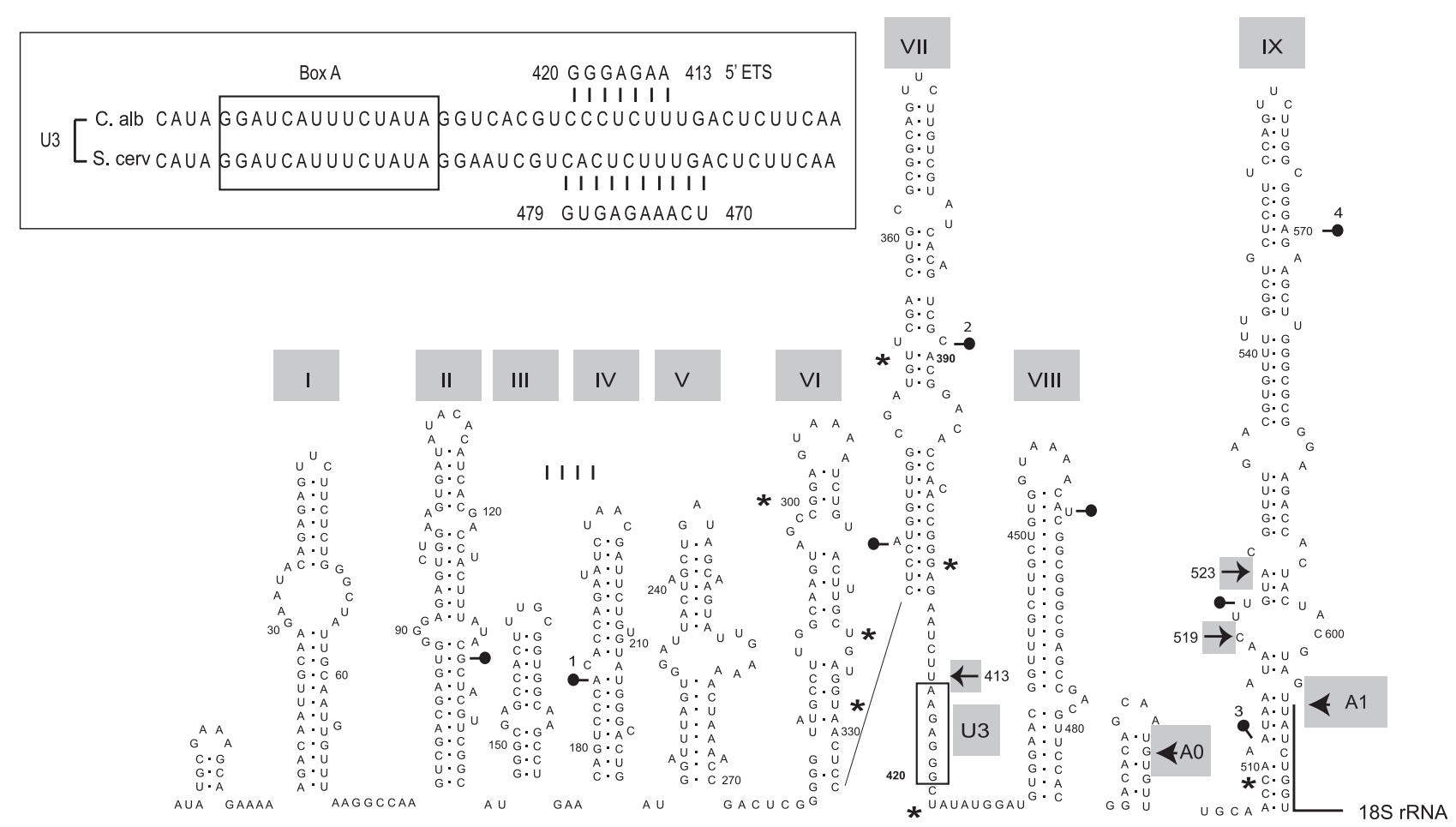

FIGURE 3. A proposed structure for the $5^{\prime}$ External Transcribed Spacer of C. albicans. The $5^{\prime}$ ETS region from the transcription start site to $10 \mathrm{nt}$ past the 18S rRNA junction was processed with the mfold algorithm (Zuker 2003) using the default values for an RNA sequence (dG $=-232 \mathrm{kcal} /$ $\mathrm{mol}$ ). The 2D structure drawing was generated using RnaVIZ (De Rijk et al. 2003) and is presented in the format of Yeh and Lee (1992). Internal processing site A0 is indicated and minor sites are indicated by arrows and numbers. The $5^{\prime}$ ends of 50-mer Northern probes listed in Figure 2E are indicated by stemmed ovals with the probe number indicated. The $3^{\prime}$ endpoints are the next unlabeled stem-oval line encountered. $\left({ }^{*}\right)$ Endpoints of sequenced RNAs. The conserved boxed region in the unpaired region of stem-loop VII indicates a U3 snoRNA complementary site. (Inset) Alignment of the 5' ends of the U3 snoRNA from C. albicans (GenBank accession no. HQ329066 and SNR17 from S. cerevisiae). The sites that are complementary between SNR17 and the S. cerevisiae 5' ETS (bottom rows) occupy similar positions in the Candida spp. sequences (top rows).

rRNA species follows the production of the $33 \mathrm{~S}$ and $32 \mathrm{~S}$ precursors. Subsequent processing at site $\mathrm{A} 2$ results in direct formation of the $20 \mathrm{~S}$ and $27 \mathrm{~S}-\mathrm{A} 2$ species (Fig. 1B, Model 1). Conversely, post-transcriptional processing would enable SSU-LSU separation before 5' ETS processing, and thus would yield a pre-rRNA product consisting of an 5' ETS $18 S$ rRNA fragment with a $3^{\prime}$ endpoint in ITS1, presumably either at site A2 or A3 (Fig. 1B, Model 2). To distinguish between these possibilities for $C$. albicans, we performed Northern analysis using oligonucleotide probes in the 5' ETS and the ITS1 region between site A2 and predicted site A3.

A probe for the $3^{\prime}$ end of the $5^{\prime}$ ETS detected a stable processed RNA species that was the approximate size of the A0-A1 fragment, as well as a larger RNA (Fig. 5A). The size of the smaller hybridizing band was estimated using labeled markers and was consistent with the size of the A0-A1 fragment detected with this probe in Figure 2E. Surprisingly, the hybridization signal from this small species diminished when cells proceeded past the diauxic transition, and a 2400nt fragment increased in abundance (Fig. 5A, lanes 1-5). The presence of the A0-A1 fragment in this larger fragment indicated that cleavage at site $\mathrm{A} 0$ and $\mathrm{A} 1$ diminished as the culture progressed past the diauxic transition and the cells began to accumulate what has been referred to as a " $23 S^{\text {" }}$ rRNA processing intermediate. A similar intermediate has been experimentally generated in S. cerevisiae by depleting the U3 snoRNA or mutation of SSU processome components (Hughes and Ares 1991; Allmang et al. 2000). A 23 S rRNA species with endpoints extending from the $5^{\prime}$ ETS to A3 has been shown to accumulate as a result of the decreased processing at sites A0, A1, and A2 (Morrissey and Tollervey 1993). Based on its size, this C. albicans $18 \mathrm{~S}$ rRNA intermediate includes all of the $5^{\prime}$ ETS and may extend into the ITS1 region.

We identified the $3^{\prime}$ endpoints for the 2400-nt rRNA using Northern analysis and a probe specific for the A2-A3 region of ITS1 (see Fig. 5E). The 2400-nt fragment could be detected in RNA from cells at the stationary growth phase, but during log-phase growth hybridization shifted to a larger RNA species consistent with a 27S-A2 pre-rRNA (Fig. 5B, lanes 2,3).

The persistence of the 2400-nt rRNA species suggests that it has a role in the normal physiology of C. albicans. The Northern hybridization data indicated that the $3^{\prime}$ end cannot be site $\mathrm{A} 2$, since it hybridizes with probe $\mathrm{c}$ distal to this site (see Fig. 5C,E). Therefore, the $3^{\prime}$ end may represent an A3 
A.

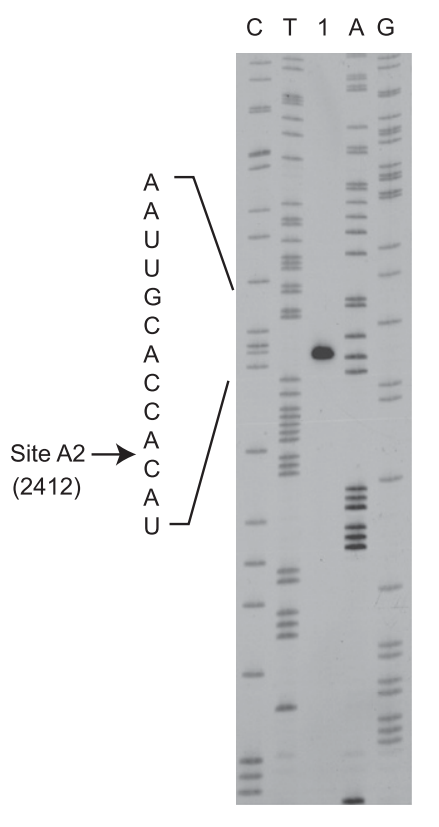

C.

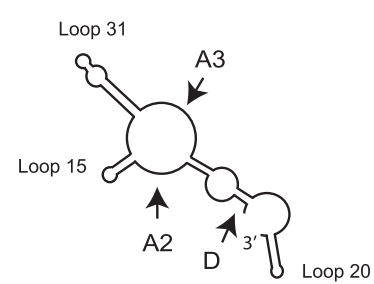

C. albicans
B.
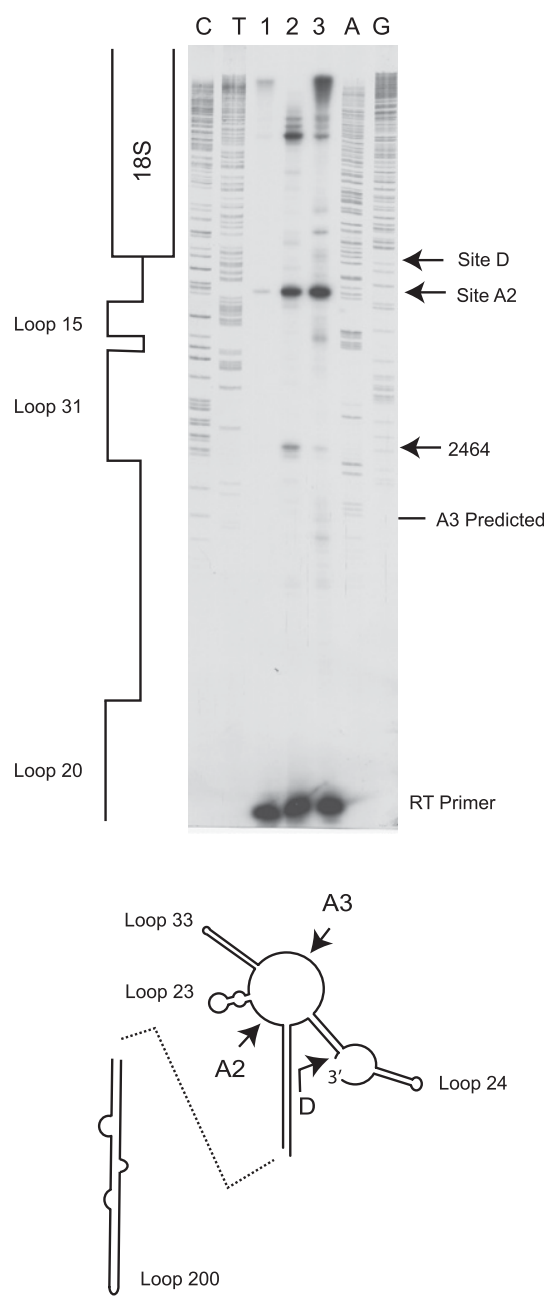

S. cerevisiae
D.

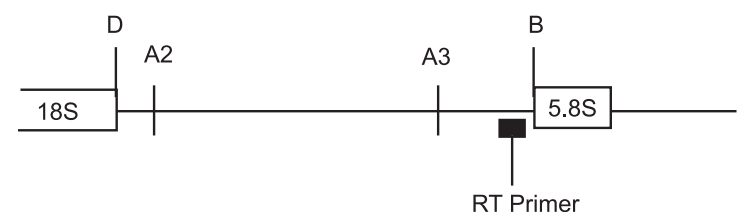

FIGURE 4. Processing in internal transcribed spacer 1. (A) Primer extension analysis using primer RR128 contained within the 25S RNA electrophoresed next to sequencing ladders generated using the same primer from cloned DNA. The location of site A2 is indicated and occurs at site 2414 relative to the transcription start site (lane 1). (B) Primer extension analysis using primer RR128 with RNA isolated from stationary phase cells (lane 1); cells after $1 \mathrm{~h}$ transfer to new medium (lane 2); and log phase cells (lane 3). The positions of loop regions shown in lane $C$ are depicted to the left of the figure. $(C)$ The folded RNA structures for S. cerevisiae ( $\mathrm{dG}=$ -112 ) and C. albicans ( $\mathrm{dG}=-33$ ) generated using the mfold algorithm (Zuker 2003). The 2D structure was generated using RnaVIZ (De Rijk et al. 2003). (D) Linear representation of the ITS1 region from C. albicans. The position of RT primer RR128 is indicated.

site. Because we were unsuccessful in identifying this site by primer extension analysis (Fig. 4), we used a standard microRNA linkering procedure as described above for the analysis of the $5^{\prime}$ ETS region (Fig. 2E). The region between the $25 \mathrm{~S}$ and $18 \mathrm{~S}$ rRNAs was excised from an agarose gel and the RNA was purified (see Fig. 5B, bracket; Material and Methods). This RNA population was ligated to a 3' linker using RNA ligase, and the RNA was reverse transcribed as described above. We used PCR primers from sequences in the distal end of the $18 \mathrm{~S}$ rRNA (Fig. 5E) to generate dsDNA using a primer that was reverse complementary to the linker sequences for the second primer of the pair. An example of the PCR products from the cloning procedure is shown in Figure 5C. For each primer, two PCR products were generated, indicating that the bulk of this RNA population linked to the $18 \mathrm{~S}$ rRNA had discrete 3' ends. These PCR fragments were purified and the DNA sequences determined.

The smaller PCR products from each primer reaction procedure corresponded to endpoints precisely at site A2 (the $18 \mathrm{~S}$ sequence is not shown). Interestingly, the larger of the fragments ended precisely at the site predicted by the models for site A3 (Fig. 5D) (see also Fig. 4). These data indicate that the 2400-nt fragment is an $18 \mathrm{~S}$ rRNA precursor containing a $5^{\prime}$ ETS leader and terminates by cleavage at site A3 in ITS1. This result also supports a model where post-transcriptional processing may be a predominant form of rRNA processing under some conditions. In the present case, this pre-18S rRNA species persists or is kept in reserve after the diauxic shift and represents an $18 \mathrm{~S}$ rRNA precursor when cells are cultured past the diauxic shift. Hereafter, this prerRNA will be referred to as a $23 \mathrm{~S}$ prerRNA by analogy with $S$. cerevisiae (Hughes and Ares 1991; Morrissey and Tollervey 1993; Allmang et al. 2000), although we do not believe this is an aberrant RNA species (see below).

\subsection{S rRNA processing}

Following cleavage at ITS1 site A2, maturation of the $5^{\prime}$ end of the 5.8S rRNA follows two pathways in S. cerevisiae, the significance of which is not entirely understood. Following RNase MRP 1 cleavage at site A3 to yield the 27SA3 rRNA, a major processing pathway generates the $5^{\prime}$ end of the $5.8 \mathrm{~S}$ rRNA by the action of $5^{\prime}-3^{\prime}$ exonucleases Rat 1 or Xrn 1 to 

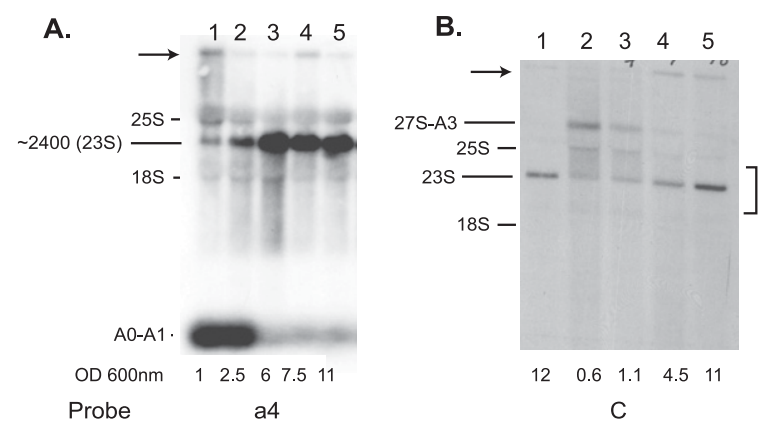

C.

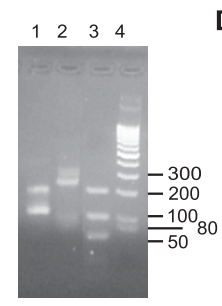

D.

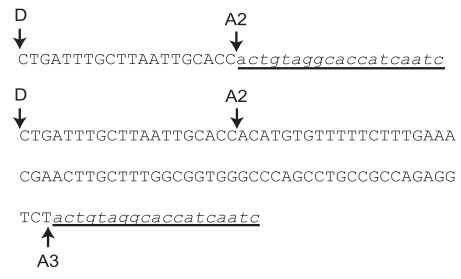

E.

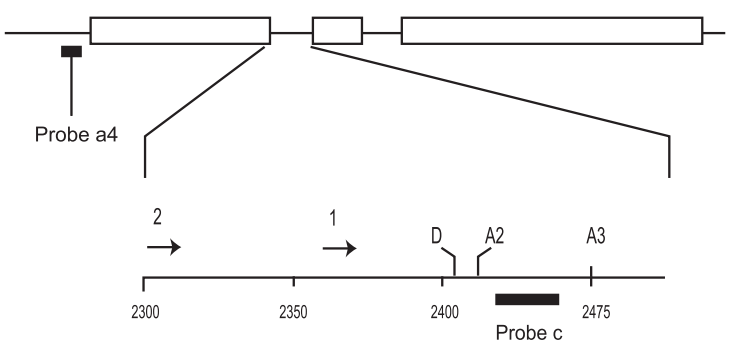

FIGURE 5. Identification of ITS1 Processing site A3 in an $18 \mathrm{~S}$ intermediate that accumulates in post-diauxic shift cells. $(A)$ Northern blot analysis reveals a small, stable element of the $5^{\prime}$ ETS and accumulation of an $18 \mathrm{~S}$ processing intermediate. Total RNA isolated at the indicated cell densities from strain SC5314 cultured in YNB medium with glucose. The location of hybridization probe a4 is indicated in $E$, below. (Arrow) Primary transcript. Locations of mature RNAs and selected processing intermediates are indicated. (B) Identification of endpoints of the $2400-n t$ pre-18S RNA. Total RNA isolated at the indicated cell densities from strain SC5314 cultured in YNB medium with glucose. The location of hybridization probe $\mathrm{c}$ is indicated in $E$, below. The bracket indicates the location of the region excised from an EtBr-stained gel for RNA isolation used in $C$, below. $(C)$ Isolation and cloning of the $3^{\prime}$ end of the 2400-nt $18 \mathrm{~S}$ rRNA intermediate. Total RNA from late log-phase cells was electrophoresed in a $1.2 \%$ TBE agarose gel and stained with EtBr. The region between the $25 \mathrm{~S}$ and18S rRNA mature forms were excised and purified (Bracket in $B$ ). The $3^{\prime}$ linkers were attached using RNA ligase, the RNAs were reverse transcribed, and PCR products were amplified using the RT primer and primers 1 and 2 in E, below. PCR products are shown electrophoresed through a $2 \%$ EtBr-stained agarose gel. (Lane 1) Products using primer 1; (lane 2) products using primer 2. (D) Sequences of the products of the RNA cloning reaction. Two products were identified and end at sites A2 and A3, respectively. The $3^{\prime}$ end of the larger RNA ends precisely at the A3 site predicted from the $S$. cerevisiae model and not at the site identified by primer extension (see Fig. 4B, position 2464). Sequence of the IDT $3^{\prime}$ linker is underlined. (E) Diagram indicating location of PCR primers and processing locations at the $18 \mathrm{~S}$ junction (site $\mathrm{D}$ ), at site $\mathrm{A} 2$, and at site A3. Numbering is relative to the transcription start site. The location of Northern hybridization probes a 4 and c are indicated. form $5.8 \mathrm{~S}$ (S). In contrast, a minor $5.8 \mathrm{~S}$ component can be generated by an endonuclease cleavage at site B1 to form $5.8 \mathrm{~S}(\mathrm{~L})$, which does not require exonuclease trimming (Fig. 1C; Faber et al. 2006). The latter species can become the predominant source for $5.8 \mathrm{~S}$ rRNA under conditions where site A3 processing is inhibited (Henry et al. 1994). We examined $5^{\prime}$ end processing of the $5.8 \mathrm{~S}$ rRNA region using primer extension analysis with a primer located in the $5.8 \mathrm{~S}$ rRNA. Two major reverse transcription stops were identified at two terminal adenine residues (Fig. 6A, lane 1). These are colinear with the $5.8 \mathrm{~S}(\mathrm{~S})$ rRNA of $S$. cerevisiae. A longer exposure of this gel identified a ladder of bands that extended $8 \mathrm{nt}$ into the ITS1 region (Fig. 6A, lane 2). This result is consistent with the exonuclease trimming of site B1. A survey of the $5^{\prime}$ ends of $5.8 \mathrm{~S}$ from a number of species was carried out by Henry et al. (1994), and the species that produced the $5.8 \mathrm{~S}(\mathrm{~L})$ forms did not display discrete endpoints nor a ladder of bands as illustrated here. In addition, we could not detect a second $5.8 \mathrm{~S}$ bands in either a 15\% acrylamide gel (Fig. 2E, lane 1) or 10\% acrylamide gel by EtBr-staining or Northern analysis (Fig. 6B, lanes 1,2). We conclude that it is unlikely that $C$. albicans produces a $5^{\prime}$-extended form of the $5.8 \mathrm{~S}$ rRNA.

The $3^{\prime}$ end of the RNA was identified through RNA cloning and attachment of the $3^{\prime}$ linker followed by reverse transcription and PCR amplification. The 5.8S rRNA was purified from a denaturing acrylamide gel stained with $\mathrm{EtBr}$ (see Fig. 6B), and linkers were attached using RNA ligase. Northern analysis using a 5.8S rRNA-specific probe could detect the linkered RNA, which comprised $<5 \%$ of the total RNA isolated (Fig. 6C). Sequencing results indicated that the $3^{\prime}$ end of this RNA is colinear with that of the RDN58 sequence of $S$. cerevisiae (Fig. 6D). This result was expected since the $3^{\prime}-5^{\prime}$ exonuclease activity of the exosome is a robust activity in S. cerevisiae and other eukaryotes (Houseley and Tollervey 2009). This would account for the lack of cloning of any RNAs with $3^{\prime}$ ends between E and C2 (see Fig. 6E). Thus, C. albicans possesses only a "short" form of the $5.8 \mathrm{~S}$ rRNA, and its ends are colinear with that of S. cerevisiae.

\section{ITS2 rRNA processing}

The ITS2 region of C. albicans shows little sequence similarity to that of S. cerevisiae, and is $77 \mathrm{nt}$ shorter (Fig. 1D). The initial processing step in $S$. cerevisiae is an endonuclease cut at site $\mathrm{C} 2$ in a $27 \mathrm{~S}-\mathrm{A} 2$ or -A3 rRNA precursor that occurs concurrently with $5.8 \mathrm{~S}$ processing (Venema and Tollervey 1995). This is followed by $3^{\prime}-5^{\prime}$ exonuclease trimming to site E to generate the $5.8 \mathrm{~S}$ rRNA and $5^{\prime}-3^{\prime}$ exonuclease trimming to form the $25 \mathrm{~S}$ rRNA (Fig. 1B,C). Processing intermediates extending from site $\mathrm{C} 2$ to site $\mathrm{B}$ are detectable by Northern analysis and are referred to as "7S" rRNAs (Fig. 1C).

The predicted folded structure of ITS2 from S. cerevisiae is an extensively internally base-paired "T-shaped" molecule that brings sites " $\mathrm{E}$ " and " $\mathrm{C} 1$ " into proximity by base pairing 
A.

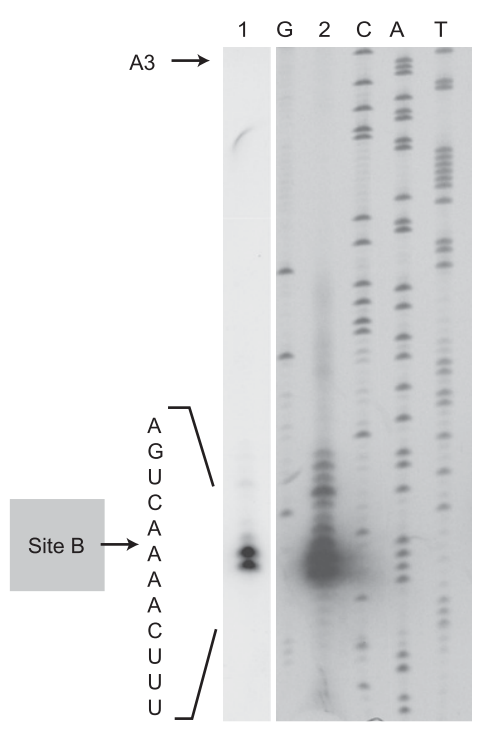

B.

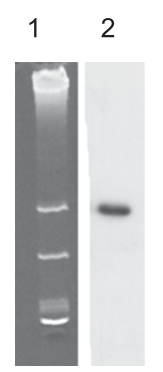

C.

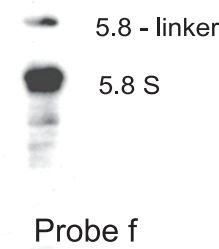

D.

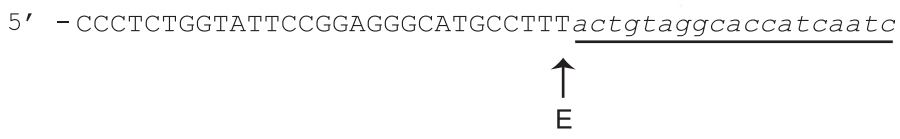

E.

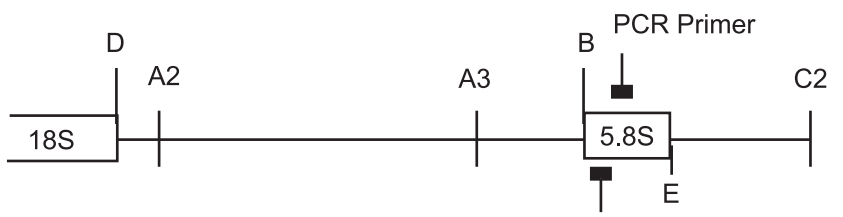

RT Primer

Probe $f$

FIGURE 6. Identification of the processed ends of the 5.8S rRNA. (A) Primer extension analysis of the $5.8 \mathrm{~S}$ rRNA $5^{\prime}$ end. Reverse transcription products using primer RR73 were electrophoresed next to a sequencing ladder generated using the same primer. (Lanes 1,2) Identical except for the exposure time of the autoradiogram. Two strong reverse-transcriptase stops are present at two sequential adenine residues and are colinear with S. cerevisiae RDN58 B1 $(S)$. (B, lane 1) EtBr-stained 10\% acrylamide gel with the identities of the major bands indicated; (lane 2) Northern blot using probe $\mathrm{f}$ of a gel similar to the one depicted in $A$. The identities of the major bands are indicated. $(C)$ Northern blot using probe $f$ of the $5.8 \mathrm{~S}$ rRNA fraction after $3^{\prime}$ linker addition. $(D)$ Sequence analysis of the linker-attached RNA identified the $3^{\prime}$ terminal residues of the 5.8S RNA. (E) Diagram of the positions of primers and the Northern probe used for these analyses.

with the $5.8 \mathrm{~S}$ and $25 \mathrm{~S}$ rRNA molecules, respectively (Yeh and Lee 1990; Cote et al. 2002). The predicted structure of the $C$. albicans molecule is remarkably similar and forms an extended loop uninterrupted by the two small branches possessed by S. cerevisiae (Fig. 7A; Lott et al. 1998; see Cote et al. 2002).

We used primer extension analysis to locate the C2 processing site by reverse transcription of a primer just $5^{\prime}$ to site C1 (Fig. 7A). RNA samples from stationary phase cells identified the $5^{\prime}$ end of the $5.8 \mathrm{~S}$ rRNA with only minor RT stops (Fig. 7B, lane 1). RNA from cells $1 \mathrm{~h}$ after transfer to new medium possessed nine RT stop sites, including one that terminated in the distal half of the $5.8 \mathrm{~S}$ rRNA (Fig. 7B, lane 2). However, RNA from log-phase cells resulted in a major stop at position 2275 that was located at the end of the long loop structure at a position similar to that of $\mathrm{C} 2$ in the $S$. cerevisiae model (Fig. 7B, lane 3; Fig. 7A, site C2; see Cote et al. 2002). Consistent with this was a decrease in the intensity of higher molecular weight bands, indicating a true RNA end (Fig. $7 \mathrm{~B}$, cf. lanes 2 and 3 ).

We also identified the $5^{\prime}$ end of the 25S rRNA (site C1) by extension of a primer located in the $25 \mathrm{~S}$ rRNA (Fig. 7C, lane 1). This result indicated that the $5^{\prime}$ end of the C. albicans 25S rRNA is colinear with that of $S$. cerevisiae.

\section{An integrated view of rRNA processing in $C$. albicans}

Direct visualization of rRNA processing events by electron microscopy and by rapid sampling techniques of pulse-chase labeling demonstrated that cotranscriptional rRNA processing is the major mode of rRNA maturation in S. cerevisiae (Osheim et al. 2004; Kos and Tollervey 2009). There are exceptions, however, and this processing pathway depends upon favorable growth conditions since a 4-min heat shock at $37^{\circ} \mathrm{C}$ was sufficient to abrogate cotranscriptional cleavage (Osheim et al. 2004; Kos and Tollervey 2009). Our evidence above indicates that post-transcriptional processing plays a role in the normal life cycle of $C$. albicans due to the accumulation of a $23 \mathrm{~S}$ rRNA precursor that persists after the diauxic transition (Fig. 5A,B). To develop a more comprehensive view of rRNA processing in C. albicans, we performed a series of Northern blots using RNA isolated from different growth phases to (1) determine processing intermediates, (2) establish the processing order, and (3) determine whether a $25 \mathrm{~S}$ rRNA precursor accumulates after the diauxic transition.

The 5' ETS A0-A1 fragment was present in the $23 \mathrm{~S}$ species during all growth stages, but was most abundant during stationary phase (Fig. 8A, probe "a4"). This probe also hybridized to the primary transcript and to the RNA immediately below. Therefore, this slightly smaller band 


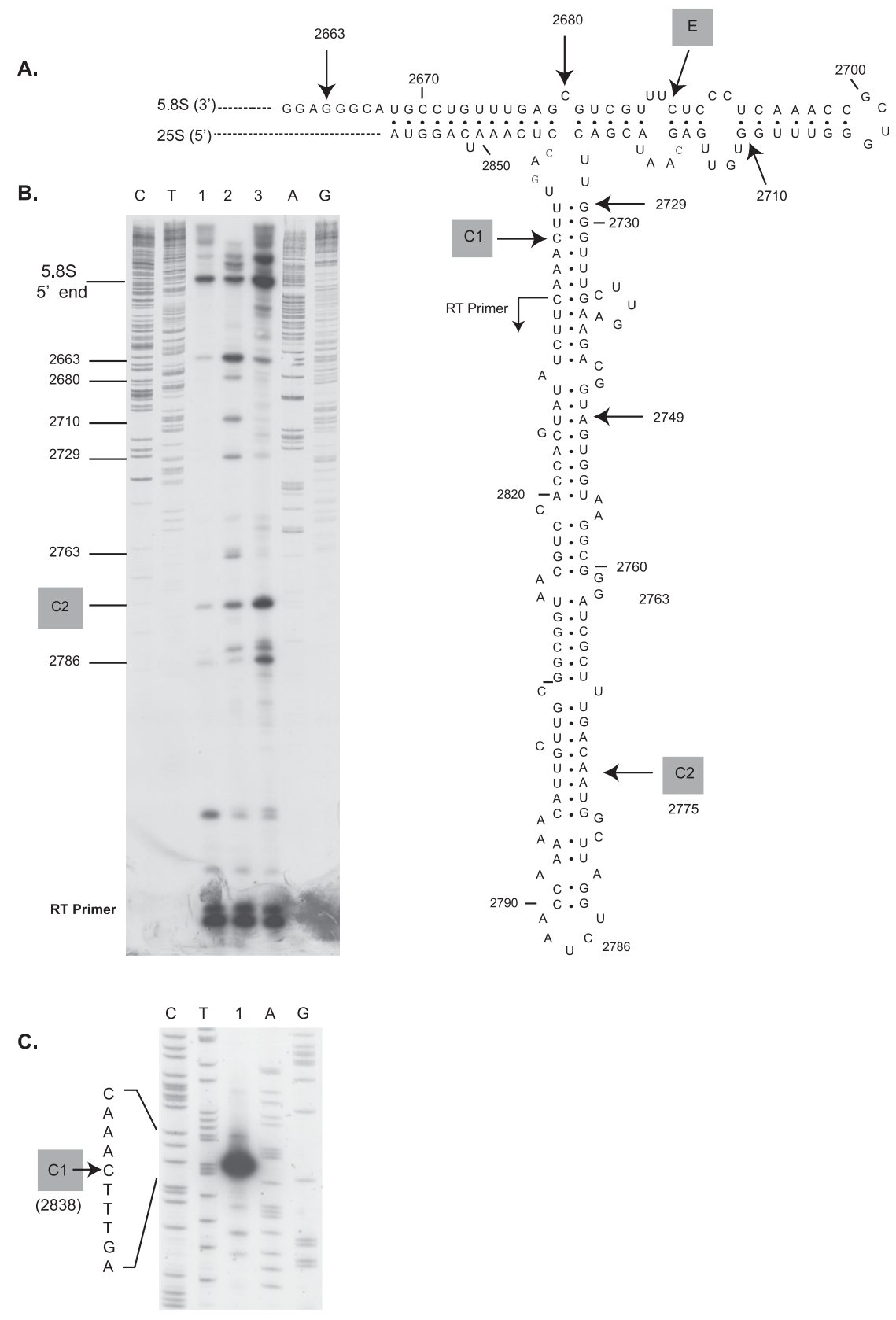

FIGURE 7. Identification of processing site C2 in ITS2. (A) The folded RNA structure was generated using the mfold algorithm (Zuker 2003) and the two-dimensional structure was generated using RnaVIZ (De Rijk et al. 2003). The positions of the major processing sites are indicated by letters in gray boxes. Minor sites are indicated by numbers alone. The 5 -end of the RT primers used for the analysis in $B$ occurs at nucleotide 2806. (B) Primer extension analysis using primer RR129 using RNA isolated from stationary phase cells (lane 1); cells after $1 \mathrm{~h}$ transfer to new medium (lane 2); and log phase cells (lane 3). (C) Primer extension analysis using primer RR76 using RNA isolated from log phase cells. The $5^{\prime}$-end of the $25 \mathrm{~S}$ rRNA is indicated.

must represent a $33 \mathrm{~S}$ species with a $5^{\prime}$ endpoint at A0 (Fig. $8 \mathrm{~A}, 33 \mathrm{~S})$. Hybridization of probe a4 is also detected as the small, stable A0-A1 fragment (Fig. 8C, lane 1).

In $S$. cerevisiae, the immediate precursor to the mature $18 \mathrm{~S}$ rRNA is a $20 \mathrm{~S}$ species representing an RNA extending from site A1 to A2 (Fig. 1B). Since the D-A2 region in $C$. albicans is only $20 \mathrm{nt}$, we wondered whether this is of a sufficient length to function as a legitimate precursor, since processing at site D2 is not absolutely required for cell survival in $S$. cerevisiae (Granneman et al. 2005). Probe d showed a hybridization pattern identical to that of probe a4, except that a band was detected immediately above the $18 \mathrm{~S}$ rRNA mature form (Fig. 8A). Therefore, even though this region of ITS1 in C. albicans is much abbreviated, an $18 \mathrm{~S}+20$-nt precursor is detectable in all but stationary phase cells. Its absence in the latter is consistent with a function as a true $18 \mathrm{~S}$ rRNA intermediate, since it is still present on the 23S rRNA precursor (Fig. 8A). In further support of this model, sequence analysis of RNAs isolated from gels in the region between the $25 \mathrm{~S}$ and $18 \mathrm{~S}$ to determine the endpoint of the $23 \mathrm{~S}$ rRNA identified a second RNA with an endpoint at A2 (Fig. 5D).

The separating cleavage of the SSU and LSU RNAs takes place in ITS1 and can occur at either site A2 or A3 (Fig. 1A). Hybridization analysis using probe $\mathrm{c}$ that lies in the A2-A3 region again detected a pattern similar to that of probe a4, except for a 27S-A2 RNA in all but the stationary phase (Fig. 8A). This RNA hybridization pattern is as expected for cotranscriptional processing. However, hybridization to the $23 \mathrm{~S}$ rRNA indicates that cleavage at site A3 also occurred, since the $23 \mathrm{~S}$ could be detected in all growth stages (Fig. 8A, probe c).

Interestingly, the A2-A3 RNA could be detected in a "7S" intermediate, an A2-E fragment, and a stable A2-A3 fragment (Fig. 8C, lane 2; Fig. 8D). These precursors were identified by hybridization with probes e and $\mathrm{f}$ (Fig. 8C, lanes 3,4). The lack of detection of either a C2-E fragment or an A3-E fragment is consistent with the final maturation steps being exonuclease trimming, by analogy with $S$. cerevisiae (Fig. 1C).

The steps in 27S-A2 maturation were investigated using probes e, f, and g (Fig. 8A). All three probes showed similar hybridization patterns to a $27 \mathrm{~S}$ species that could either have its endpoint at A2 or A3, since a 64-nt difference may not be resolved on these gels. However, since stationary phase cells showed either a complete lack or minimal hybridization, this precludes the 

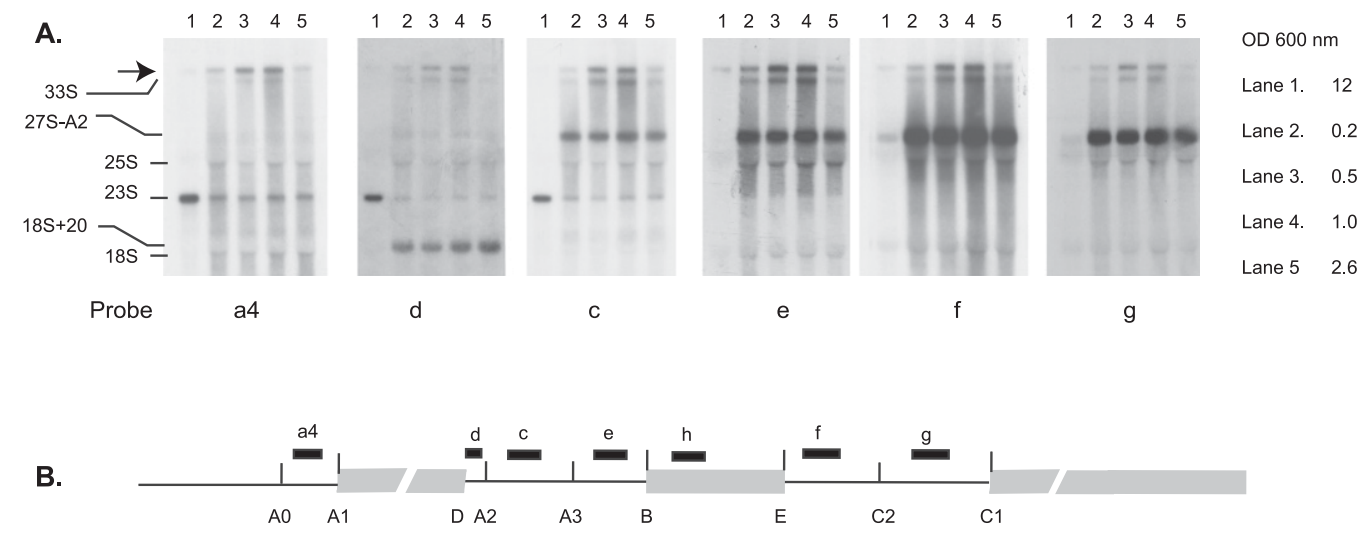

C.

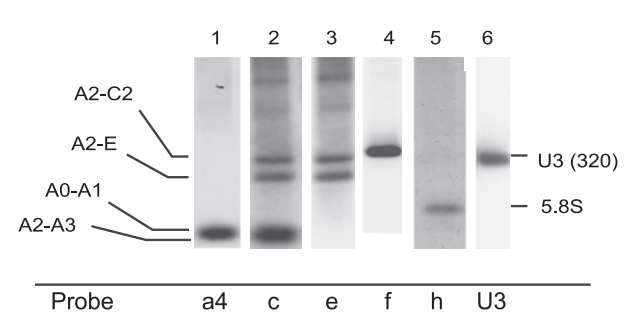

D.

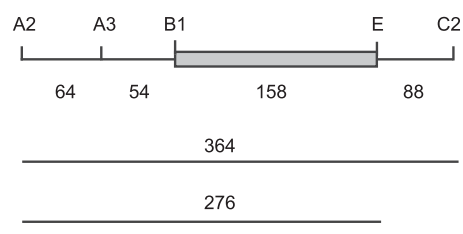

$64 \quad 158$

FIGURE 8. Processing leading to the separation of the Small and Large rRNAs. (A) Northern blots using RNA isolated at the indicated cell densities. (B) Locations of the probes used for Northern blots. (C) Enlargements of the bottom portions of Northern blots using RNA isolated form log phase cells. $(D)$ Diagram depicting the $5.8 \mathrm{~S}$ rRNA region. The numbers indicate the length of each segment in nucleotides. The lines depict the length and location of the intermediates shown in $C$.

significant accumulation and persistence of an LSU precursor rRNA.

\section{DISCUSSION}

Structure and functions of the protein and RNA components of ribosomes are evolutionarily conserved in all living organisms. The rRNA processing pathways are also generally conserved, yet rely on highly divergent spacer regions that are nonetheless functionally similar (Fedoroff 1979). When we analyzed maturation of the polycistronic rRNA transcript in the ascomycete fungus $C$. albicans, we observed the accumulation of a $23 \mathrm{~S}$ rRNA precursor as the cells passed the diauxic transition (Fig. 5A). This lends support to the hypothesis that the cells sense certain growth conditions where post-transcriptional processing is needed. Indeed, the normal habitat of C. albicans is a part of the normal gastrointestinal flora where the nutrient resources are limited, which is quite different from rich laboratory culture media. C. albicans also possesses a number of defined developmental stages, including the formation of true hyphae, where transport of translational machinery including pre-rRNAs to distant sites is possible. Investigations into the fate of the $23 \mathrm{~S}$ molecule during development are currently in progress.

Nevertheless, pre-rRNA processing in C. albicans is very similar to that of other eukaryotes (Table 1; Venema and
Tollervey 1999; Henras et al. 2008). The separation of the SSU and LSU pre-rRNA components occurs by cleavage at site A3 or the U3 snoRNA-dependent site A2 in ITS1 (Fig. 9). These cleavage positions are structurally conserved with those of S. cerevisiae, as are the $5^{\prime}$ and $3^{\prime}$ ends of the $5.8 \mathrm{~S}$ prerRNA. However, only a single form of the $5.8 \mathrm{~S}$ rRNA was detected that corresponds to the S. cerevisiae $5.8 \mathrm{~S}(\mathrm{~S})$ form.

TABLE 1. Candida albicans rRNA processing sites

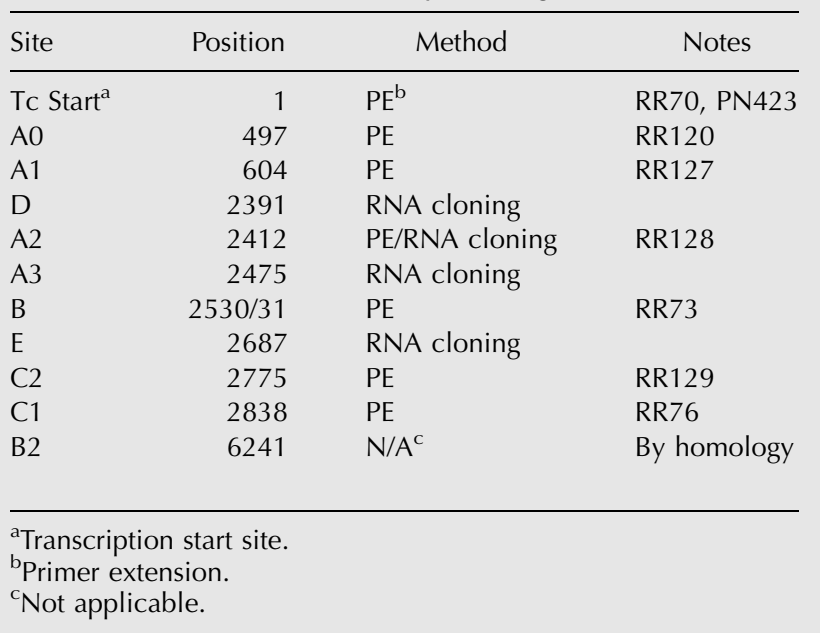


A.

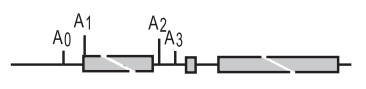

Processing A0, A1

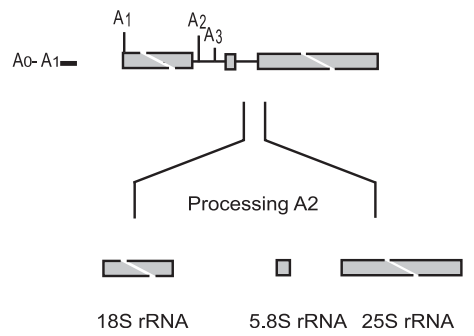

B.
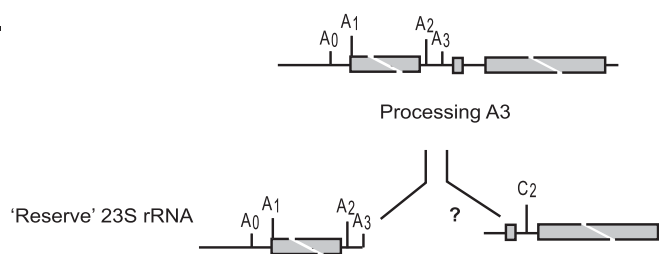

Processing A0, A1, A2

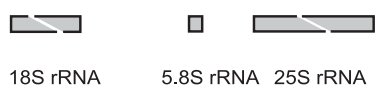

FIGURE 9. A model for rRNA processing in Candida albicans. A diagram of the overall structure of the primary rRNA transcript and proposed processing steps for C. albicans. (A) A model for cotranscriptional processing. Processing occurs sequentially from the U3 snoRNA-dependent sites at A0, A1, and A2. 5.8S rRNA processing at site B1 can proceed through either of two pathways to form the $5.8 \mathrm{~S}$ B1 (S) or B1 (L) products. (B) The separation of the large and small ribosomal subunit RNAs occurs at site A3 before processing at sites A0, A1, or A2. The 18S rRNA precursor (23S) has two fates: during exponential growth the $23 \mathrm{~S}$ is rapidly processed to the $18 \mathrm{~S}$ mature form, but accumulates as the cells proceed through the diauxic transition and enter stationary phase (reserve copy). Whether the $23 \mathrm{~S}$ reserve copy is functional is not known, although its levels do not decrease from early stationary phase to true stationary phase or quiescent cells (data not shown).

The formation of $5.8 \mathrm{~S}$ B1(S) depends upon endonucleolytic cleavage at site $\mathrm{A} 3$, which in $\mathrm{S}$. cerevisiae is catalyzed by a ribonucleoprotein complex RNase MRP1 (Schmitt and Clayton 1993). MRP1 is composed of an RNA component $340 \mathrm{nt}$ in length encoded by $N M E 1$, and nine protein components (Houser-Scott et al. 2002). The MRP1 RNA has been identified in C. albicans and is unusually long (2226 nt) (Piccinelli et al. 2005). A single MRP protein component has been annotated in the C. albicans database (POP4; $19.5567)$, so it will be of interest to identify other protein components of this complex and to determine whether the unusual length of this RNA is necessary for processing at site A3 as described above.

We identified processing site $\mathrm{A} 3$ by isolation of the $23 \mathrm{~S}$ pre-rRNA and sequencing the $3^{\prime}$ end because we could not detect A3 by primer extension analysis (Fig. 4). The latter result may be expected, since the $5.8 \mathrm{~S} \mathrm{~B} 1(\mathrm{~S})-\mathrm{A} 3$ fragment should be unstable due to Rat1p/Xrn1 exonucleolytic digestion (Venema and Tollervey 1999). A C. albicans ortholog has been identified (RAT1; orf19.4681), and interestingly, homozygous mutants are defective in hyphal development (An et al. 2004).

The identification of the $23 \mathrm{~S}$ pre-rRNA as a normal feature of C. albicans growth was unexpected since depletion or protein truncation of SSU processome components also leads to a $23 \mathrm{~S}$ or $22 \mathrm{~S}$ rRNA with 5' ETS and A3 endpoints (Baserga et al. 1997; Dunbar et al. 1997; Lee and Baserga 1997; Dragon et al. 2002; Gallagher et al. 2004; Osheim et al. 2004; Granneman and Baserga 2005). However, Hughes and Ares determined that the $23 \mathrm{~S}$ pre-rRNA can be detected at low levels in wild-type S. cerevisiae and appears to be a normal component of the processing pathway (Hughes and Ares 1991; also see Billy et al. 2000; Wehner and Baserga 2002). The latter results mirror those depicted here, except that the
$23 \mathrm{~S}$ rRNA accumulates during stationary phase and is barely detectable only $1 \mathrm{~h}$ after transfer of stationary-phase cells to fresh growth media (Fig. 8A). This suggests that this rRNA precursor may be functional and that a specific posttranscriptional processing program is utilized in cells after the diauxic transition.

On the other hand, evidence has been recently presented that the 23S rRNA in S. cerevisiae is nonfunctional because cleavage at site $\mathrm{A} 3$ before site $\mathrm{A} 2$ precludes the generation of an RNA structure competent for further maturation (i.e., cleavage at site D) (Lamanna and Karbstein 2011). The predictions from this model indicate that the C. albicans $23 \mathrm{~S}$ rRNA would also be nonfunctional.

C. albicans is a dimorphic fungus that readily forms true hyphae under appropriate conditions. In general, rapidly proliferating cells are poor hyphae formers, whereas the opposite is true of stationary phase cells (Sudbery 2011). Carbon and nitrogen limitation are robust stimuli for hyphae formation and seem to mirror the conditions shown here for $23 \mathrm{~S}$ rRNA accumulation. In S. cerevisiae and other eukaryotic organisms including humans, subjecting cells to a stressor such as glucose exhaustion leads to an immediate cessation of translation and the dissolution of polysomes (Brengues, 2005 \#165) SSU but not LSU components along with the associated mRNA and other translation factors are sequestered into stress granules and can return to active translation if the stress is relieved within an appropriate time (Teixeira et al. 2005; Thomas et al. 2011). Perhaps the $23 \mathrm{~S}$ rRNA accumulation represents a variation on this theme and represents a priming mechanism for a rapid cellular response to developmental cues. We have tested cultures up to 6-d-old and have seen no noticeable change in the levels of this RNA after the diauxic shift (data not shown). 
We speculate that this RNA plays a role in $C$. albicans differentiation and a compelling piece of evidence comes from the cellular response to the presence of $\mathrm{Hb}$. Two of seven genes identified from a differential display screening for genes regulated by $\mathrm{Hb}$ are necessary for rRNA processing at site D (Pendrak et al. 2004). The orthologs of NOB1 (HBR3) and FAP7 (HBR1) are both up-regulated in the presence of $\mathrm{Hb}$ after cells have passed the diauxic transition (Pendrak et al. 2004). Hb is an inducer of hyphal differentiation (Pendrak and Roberts 2007) and cells heterozygous for HBR1 (FAP7) are defective in hyphae formation (ML Pendrak and DD Roberts, unpubl.). Whether this defect is directly related to SSU rRNA maturation awaits testing.

After the separation of the LSU and SSU pre-rRNAs, processing at site $\mathrm{D}$ to generate the mature $18 \mathrm{~S}$ rRNA would presumably occur in the cytoplasm as is it does in S. cerevisiae (Granneman et al. 2005), although this remains to be tested. The D-A2 region of this pre-rRNA is only $20 \mathrm{nt}$, and to our knowledge is the shortest reported in the literature. This region can be deleted in $S$. cerevisiae without affecting cell growth (Allmang et al. 1996) and is consistent with the structural similarity of the remaining region to the C. albicans RNA (see Fig. 4C).

Processing of the LSU pre-rRNAs appears to follow that of the $S$. cerevisiae model in a number of aspects, including a structural similarity of ITS2 and the position of cleavage site C2 (see Fig. 7). However, we could not detect the presence of a $5.8 \mathrm{~S}(\mathrm{~L})$ form, nor could we detect a $7 \mathrm{~S}$ species with endpoints at B and C2 (Figs. 6, 8C). However, we could identify longer fragments extending from site $\mathrm{C} 2$ to sites A2 and A3 in ITS1 (Fig. 7C). This indicates that processing in this region may depart from the $S$. cerevisiae model.

S. cerevisiae has been a successful model organism to study RNA metabolism (Venema and Tollervey 1999; FromontRacine et al. 2003). However, comparative studies with other fungi including $C$. albicans reveal variations that suggest $S$. cerevisiae to be atypical. For instance, splicesomal RNA domains defined as "fungal-specific" in U2 and U5 RNAs are actually unique to Saccharomyces spp (Mitrovich and Guthrie 2007). On the other hand, the NME1 RNA in C. albicans is unusually long when compared with other fungi and metazoans (Piccinelli et al. 2005). Therefore, it is not entirely unexpected that $C$. albicans rRNA processing differs in several fundamental ways from that of $S$. cerevisiae.

Collectively, our data indicate that C. albicans exhibits unique regulation of its rRNA processing. During exponential growth, a stable 108-nt fragment is generated by processing at sites A0 and A1 from a larger 2400-nt (23S pre-rRNA) precursor that may correspond to the $23 \mathrm{~S}$ species seen in $S$. cerevisiae (Hughes and Ares 1991; Gallagher et al. 2004). Surprisingly, as cells enter the diauxic transition this processing decreases $\sim 90 \%$, and a stable intermediate accumulates and persists (Fig. 5A). Therefore, C. albicans relies on both cotranscriptional and post-transcriptional modes of pre-rRNA processing, and this responsiveness to its environment may reflect its growth as a commensal and opportunistic pathogen under restricted nutrient availability in a human host.

\section{MATERIALS AND METHODS}

C. albicans wild-type strain SC5314 was used throughout this work (Gillum et al. 1984). Yeast cells were cultured in YPD medium (yeast extract, peptone, dextrose) (Sherman 1991) at $30^{\circ} \mathrm{C}$ for $24 \mathrm{~h}$ and transferred to new medium to begin cell growth for RNA analyses. RNA was isolated using the hot phenol method (Kohrer and Domdey 1991). Low molecular weight RNA was isolated from total RNA with a mirVana miRNA isolation kit using conditions suggested by the manufacturer (Ambion). Northern blot analysis was carried out using total RNA that had been glyoxylated at $55^{\circ} \mathrm{C}$ for $1 \mathrm{~h}$ and electrophoresed through a $25-\mathrm{cm}, 1.2 \%$ agarose gel in BPTE buffer (Sambrook and Russell 2001) for $5 \mathrm{~h}$ at 125 volts. RNA transfer to a Genescreen Plus membrane was carried out by downward capillary blotting overnight using 20X SSPE (Sambrook and Russell 2001). Hybridization reactions using ${ }^{32} \mathrm{P}$-end-labeled oligonucleotides were carried out at $42^{\circ} \mathrm{C}$ for $16 \mathrm{~h}$ in Ultrahyb-Oligo (Ambion) and washed sequentially in buffers, all containing $0.1 \%$ SDS with $2 \mathrm{xSSC}, 1 \mathrm{xSSC}$, and $0.1 \mathrm{X}$ SSC for $20 \mathrm{~min}$ each at $55^{\circ} \mathrm{C}$. Blots were exposed to film at $-80^{\circ} \mathrm{C}$.

RNA isolation from agarose gels was carried out with a Zymoclean Gel RNA Recovery Kit (Zymo Research Corporation) using the protocol suggested by the manufacturer. RNA isolation from polyacrylamide gels used the "crush and soak" method as outlined in the miRCat Cloning Kit technical manual (Integrated DNA Technologies [IDT]) using DTR gel-filtration columns (Edge Biosystems). RNA linkering was performed using a $3^{\prime}$ activated linker (IDT) and RNA Ligase (New England Biolabs) in ligase buffer lacking ATP following the instructions provided in the IDT technical manual (miRCat Cloning kit, IDT).

Identification of cloned RNAs was accomplished by reverse transcription using a primer complementary to the IDT 3-linker (RR117) (Table 2) using Superscript III reverse transcriptase (Invitrogen). PCR products were generated using upstream primers as indicated in the figures, coupled with RR117. These products were cloned into plasmid vector pCRII (Invitrogen) and sequenced using primer sites located in the plasmid vector.

Primer extension analyses were carried out following standard protocols (Sambrook and Russell 2001) using $10 \mu \mathrm{g}$ of total RNA and Superscript III Reverse Transcriptase (Invitrogen) in a 1-h extension reaction. Briefly, $20 \mathrm{fmol}$ of end-labeled primers were annealed by incubation for $5 \mathrm{~min}$ at $95^{\circ} \mathrm{C}$, followed by an additional $5 \mathrm{~min}$ in an ice bath. End-labeled oligonucleotide primers were prepared using Polynucleotide Kinase (New England Biolabs) and $\left[\gamma-{ }^{32} \mathrm{P}\right]$ ATP. The specific activity obtained was typically $1 \times 10^{6} \mathrm{cpm} / \mathrm{pmol}$ (Sambrook and Russell 2001). Extension products were visualized by electrophoresis through either a $6 \%$ or $8 \%$ acrylamide/8M urea gel in TTE buffer ( $10 \mathrm{mM}$ Tris base, $2.5 \mathrm{mM}$ Taurine, $0.5 \mathrm{mM}$ EDTA), followed by autoradiography. Sequencing templates for primer extension analysis were obtained from PCR products generated using Platinum TAQ and cloned using the TA-TOPO system into vector pCR2.1 (Invitrogen) using C. albicans SC4315 total genomic DNA as template. Amplification of the $5^{\prime}$ ETS region used primers RR127 and PN437 to generate an 1166-bp product extending upstream of the start of the $18 \mathrm{~S}$ gene (plasmid pETS1). The region encompassing ITS1 and ITS2 was 
TABLE 2. Oligonucleotides used for hybridization probes and PCR reactions

\begin{tabular}{|c|c|c|}
\hline Oligo & Position $^{\mathrm{a}}$ & Sequence $5^{\prime}$ to $3^{\prime}$ \\
\hline a4 & 5' ETS (184) & CССGCСAAGACTGGAAGGAGCAGCCAAAAACACGTTCAAACCGTACAAG \\
\hline a3 & 5' ETS (376) & ССАCAGCAAGCAAACCGTTCСАСАTССАTATAGСССТСТTAА \\
\hline a2 & 5' ETS (453) & GGGACTGTTCAGGCTTGCCACCGCAAAGTGGCTCGCССАTGC \\
\hline a1 & 5' ETS (568) & CGACAAGAACTGCCGCGCACGTCGAACATCGCCAACСАTGGA \\
\hline P1 & $5^{\prime}$ ETS (477) & CGTTCCACGGACACAGC \\
\hline P2 & 5' ETS (386) & CGCACGGACACCACACC \\
\hline P3 & 5' ETS (280) & TATGCCTTGGCAAGTAGCC \\
\hline$d$ & ITS1 (2411) & GGTGCAATTAAGCAAATCAG \\
\hline c & ITS1 (2473) & GTTTAGACCTCTGGCGGCAGGCTGGGCCCACCGCCAAAGCAAGTTTGTTTC \\
\hline e & ITS1 (2530) & TTGACTATTAGTAATAATCTGGTGTGACAAGTTGATAAAAAATTGGTTGT \\
\hline $\mathrm{h}$ & $5.8 \mathrm{~S}(2592)$ & СGTATCGCATTTCGСТGCGTTCTTCATCGATGCGAGAGCCAAGAGATCCG \\
\hline f & ITS2 (2739) & CAAGCAAACCCAAGTCGTATTGCTCAACACCAAACCCAGCGGTTGAGGG \\
\hline g & ITS2 (2825) & CGTGGTCGACGTTACCGCCGCAAGCAATGTTTTTGGTTAGACCTAAGCCA \\
\hline U3 & U3 snoRNA & GAGGGTACAAGGGTAATCTCACTCATCAACCAAGTTGGATTCAGTGGCTC \\
\hline Primer 1 & 18S PCR (2177) & AAGCGCAAGTCATCAGCTTGC \\
\hline Primer 2 & 18S PCR (2300) & TCTGGAACCGAGAAGCTGGTC \\
\hline RR117 & RT/PCR Primer & GATTGATGGTCGCTACAG \\
\hline PN437 & PCR (-453) & ATTGCCATGGCCTGAGGATG \\
\hline RR70 & 5'ETS (138) & CGTAGCGTATAAAGTAGGTCG \\
\hline RR120 & 5' ETS (602) & TACGTAGTAGTGGTCTTGG \\
\hline RR127 & 5' ETS (713) & CTGATTTAATGAGCCATTCGC \\
\hline RR128 & ITS1 (2528) & TACGTAGTAGTGGTCTTGG \\
\hline RR73 & $5.8 \mathrm{~S}(2577)$ & TGCGTTCTTCATCGATGCG \\
\hline RR118A & $5.8 \mathrm{~S}(2559)$ & CGCATCGATGAAGAACGCA \\
\hline RR129 & ITS2 (2834) & GAAGATATACGTGGTGGACG \\
\hline RR76 & $25 S$ (2935) & САСТCGCCGCTACTGAGGC \\
\hline
\end{tabular}

'Location of the 5 ' end of probe relative to the start site of transcription.

amplified using primers RR1 and RR76 to generate a 636-bp product (plasmid pITS12) (Table 2). Sequencing reactions were carried out using the Sequenase Plasmid Quick Denature kit (United States Biochemical).

\section{ACKNOWLEDGMENTS}

This research was supported by the Intramural Research Program of the National Institutes of Health, National Cancer Institute, Center for Cancer Research. We thank Dr. Malgorzata Ptaszynska for her comments on the manuscript.

Received May 5, 2011; accepted September 16, 2011.

\section{REFERENCES}

Allmang C, Henry Y, Wood H, Morrissey JP, Petfalski E, Tollervey D. 1996. Recognition of cleavage site $\mathrm{A}(2)$ in the yeast pre-rRNA. RNA 2: 51-62.

Allmang C, Mitchell P, Petfalski E, Tollervey D. 2000. Degradation of ribosomal RNA precursors by the exosome. Nucleic Acids Res 28: $1684-1691$.

An HS, Lee KH, Kim J. 2004. Identification of an exoribonuclease homolog, CaKEM1/CaXRN1, in Candida albicans and its characterization in filamentous growth. FEMS Microbiol Lett 235: 297-303.

Arnaud M, Costanzo M, Skrzypek M, Shah P, Binkley G, Lane C, Miyasato S, Sherlock G. 2007. Sequence resources at the Candida Genome Database (CGD). Nucleic Acids Res 35: D452-D456.
Baserga SJ, Agentis TM, Wormsley S, Dunbar DA, Lee S. 1997. Mpp10p, a new protein component of the U3 snoRNP required for processing of $18 \mathrm{~S}$ rRNA precursors. Nucleic Acids Symp Ser 36: 64-67.

Beltrame M, Tollervey D. 1995. Base pairing between U3 and the preribosomal RNA is required for $18 \mathrm{~S}$ rRNA synthesis. EMBO J 14: 4350-4356.

Billy E, Wegierski T, Nasr F, Filipowicz W. 2000. Rcllp, the yeast protein similar to the RNA 3 '-phosphate cyclase, associates with $\mathrm{U} 3$ snoRNP and is required for $18 \mathrm{~S}$ rRNA biogenesis. EMBO J 19: 2115-2126.

Cherry JM, Ball C, Dolinski K, Dwight S, Harris M, Matese JC, Sherlock G, Binkley G, Jin H, Weng S, et al. 2002. Saccharomyces Genome Database http://genome-www.stanford.edu/Saccharomyces/. Vol 2002.

Cote CA, Greer CL, Peculis BA. 2002. Dynamic conformational model for the role of ITS2 in pre-rRNA processing in yeast. RNA 8: 786-797.

De Rijk P, Wuyts J, De Wachter R. 2003. RnaViz 2: an improved representation of RNA secondary structure. Bioinformatics 19: 299-300.

Dragon F, Gallagher JE, Compagnone-Post PA, Mitchell BM, Porwancher KA, Wehner KA, Wormsley S, Settlage RE, Shabanowitz J, Osheim Y, et al. 2002. A large nucleolar U3 ribonucleoprotein required for $18 \mathrm{~S}$ ribosomal RNA biogenesis. Nature 417: 967-970.

Dunbar DA, Wormsley S, Agentis TM, Baserga SJ. 1997. Mpp10p, a U3 small nucleolar ribonucleoprotein component required for pre-18S rRNA processing in yeast. Mol Cell Biol 17: 5803-5812.

Faber AW, Vos HR, Vos JC, Raue HA. 2006. 5' -end formation of yeast 5.8SL rRNA is an endonucleolytic event. Biochem Biophys Res Commun 345: 796-802.

Fedoroff NV. 1979. On spacers. Cell 16: 697-710. 
Fromont-Racine M, Senger B, Saveanu C, Fasiolo F. 2003. Ribosome assembly in eukaryotes. Gene 313: 17-42.

Gallagher JE, Dunbar DA, Granneman S, Mitchell BM, Osheim Y, Beyer AL, Baserga SJ. 2004. RNA polymerase I transcription and pre-rRNA processing are linked by specific SSU processome components. Genes Dev 18: 2506-2517.

Gillum AM, Tsay EY, Kirsch DR. 1984. Isolation of the Candida albicans gene for orotidine- $5^{\prime}$-phosphate decarboxylase by complementation of $S$. cerevisiae ura3 and E. coli pyrF mutations. Mol Gen Genet 198: 179-182.

Granneman S, Baserga SJ. 2004. Ribosome biogenesis: of knobs and RNA processing. Exp Cell Res 296: 43-50.

Granneman S, Baserga SJ. 2005. Crosstalk in gene expression: coupling and co-regulation of rDNA transcription, pre-ribosome assembly and pre-rRNA processing. Curr Opin Cell Biol 17: 281286.

Granneman S, Nandineni MR, Baserga SJ. 2005. The putative NTPase Fap7 mediates cytoplasmic 20S pre-rRNA processing through a direct interaction with Rps14. Mol Cell Biol 25: 10352-10364.

Henras AK, Soudet J, Gerus M, Lebaron S, Caizergues-Ferrer M, Mougin A, Henry Y. 2008. The post-transcriptional steps of eukaryotic ribosome biogenesis. Cell Mol Life Sci 65: 2334-2359.

Henry Y, Wood H, Morrissey JP, Petfalski E, Kearsey S, Tollervey D. 1994. The $5^{\prime}$ end of yeast $5.8 \mathrm{~S}$ rRNA is generated by exonucleases from an upstream cleavage site. EMBO J 13: 2452-2463.

Houseley J, Tollervey D. 2009. The many pathways of RNA degradation. Cell 136: 763-776.

Houser-Scott F, Xiao S, Millikin CE, Zengel JM, Lindahl L, Engelke DR. 2002. Interactions among the protein and RNA subunits of Saccharomyces cerevisiae nuclear RNase P. Proc Natl Acad Sci 99: 2684-2689.

Hughes JM, Ares M Jr. 1991. Depletion of U3 small nucleolar RNA inhibits cleavage in the $5^{\prime}$ external transcribed spacer of yeast preribosomal RNA and impairs formation of $18 \mathrm{~S}$ ribosomal RNA. EMBO J 10: 4231-4239.

Jones T, Federspiel NA, Chibana H, Dungan J, Kalman S, Magee BB, Newport G, Thorstenson YR, Agabian N, Magee PT, et al. 2004. The diploid genome sequence of Candida albicans. Proc Natl Acad Sci 101: 7329-7334.

Kohrer K, Domdey H. 1991. Preparation of high molecular weight RNA. Methods Enzymol 194: 398-405.

Kos M, Tollervey D. 2009. Yeast pre-rRNA processing and modification occur cotranscriptionally. Mol Cell 37: 809-820.

Lamanna AC, Karbstein K. 2011. An RNA conformational switch regulates pre-18S rRNA cleavage. J Mol Biol 405: 3-17.

Lee SJ, Baserga SJ. 1997. Functional separation of pre-rRNA processing steps revealed by truncation of the U3 small nucleolar ribonucleoprotein component, Mpp10. Proc Natl Acad Sci 94: 13536-13541.

Lott TJ, Burns BM, Zancope-Oliveira R, Elie CM, Reiss E. 1998. Sequence analysis of the internal transcribed spacer 2 (ITS2) from yeast species within the genus Candida. Curr Microbiol 36: 63-69.

Mitrovich QM, Guthrie C. 2007. Evolution of small nuclear RNAs in S. cerevisiae, C. albicans, and other hemiascomycetous yeasts. RNA 13: $2066-2080$.

Morrissey JP, Tollervey D. 1993. Yeast snR30 is a small nucleolar RNA required for 18S rRNA synthesis. Mol Cell Biol 13: 2469-2477.
Needleman SB, Wunsch CD. 1970. A general method applicable to the search for similarities in the amino acid sequence of two proteins. J Mol Biol 48: 443-453.

Osheim YN, French SL, Keck KM, Champion EA, Spasov K, Dragon F, Baserga SJ, Beyer AL. 2004. Pre-18S ribosomal RNA is structurally compacted into the SSU processome prior to being cleaved from nascent transcripts in Saccharomyces cerevisiae. Mol Cell 16: 943-954.

Pendrak ML, Roberts DD. 2007. Hemoglobin is an effective inducer of hyphal differentiation in Candida albicans. Med Mycol 45: 61-71.

Pendrak ML, Yan SS, Roberts DD. 2004. Sensing the host environment: recognition of hemoglobin by the pathogenic yeast Candida albicans. Arch Biochem Biophys 426: 148-156.

Piccinelli P, Rosenblad MA, Samuelsson T. 2005. Identification and analysis of ribonuclease $\mathrm{P}$ and MRP RNA in a broad range of eukaryotes. Nucleic Acids Res 33: 4485-4495.

Rustchenko EP, Curran TM, Sherman F. 1993. Variations in the number of ribosomal DNA units in morphological mutants and normal strains of Candida albicans and in normal strains of Saccharomyces cerevisiae. J Bacteriol 175: 7189-7199.

Sambrook J, Russell D. 2001. Molecular cloning: A laboratory manual. Cold Spring Harbor Laboratory Press, Cold Spring Harbor, NY.

Schmitt ME, Clayton DA. 1993. Nuclear RNase MRP is required for correct processing of pre-5.8S rRNA in Saccharomyces cerevisiae. Mol Cell Biol 13: 7935-7941.

Sherman F. 1991. Getting started with yeast. Methods Enzymol 194: $3-21$.

Sudbery PE. 2011. Growth of Candida albicans hyphae. Nat Rev Microbiol 9: 737-748.

Teixeira D, Sheth U, Valencia-Sanchez MA, Brengues M, Parker R. 2005. Processing bodies require RNA for assembly and contain nontranslating mRNAs. RNA 11: 371-382.

Thomas MG, Loschi M, Desbats MA, Boccaccio GL. 2011. RNA granules: the good, the bad and the ugly. Cell Signal 23: 324-334.

Venema J, Tollervey D. 1995. Processing of pre-ribosomal RNA in Saccharomyces cerevisiae. Yeast 11: 1629-1650.

Venema J, Tollervey D. 1999. Ribosome synthesis in Saccharomyces cerevisiae. Annu Rev Genet 33: 261-311.

Venema J, Henry Y, Tollervey D. 1995. Two distinct recognition signals define the site of endonucleolytic cleavage at the $5^{\prime}$-end of yeast $18 \mathrm{~S}$ rRNA. EMBO J 14: 4883-4892.

Wehner KA, Baserga SJ. 2002. The $\sigma^{70}$-like motif: a eukaryotic RNA binding domain unique to a superfamily of proteins required for ribosome biogenesis. Mol Cell 9: 329-339.

Wickes B, Staudinger J, Magee BB, Kwon-Chung KJ, Magee PT, Scherer S. 1991. Physical and genetic mapping of Candida albicans: several genes previously assigned to chromosome 1 map to chromosome $\mathrm{R}$, the rDNA-containing linkage group. Infect Immun 59: 2480-2484.

Yeh LC, Lee JC. 1990. Structural analysis of the internal transcribed spacer 2 of the precursor ribosomal RNA from Saccharomyces cerevisiae. J Mol Biol 211: 699-712.

Yeh LC, Lee JC. 1992. Structure analysis of the 5' external transcribed spacer of the precursor ribosomal RNA from Saccharomyces cerevisiae. J Mol Biol 228: 827-839.

Zuker M. 2003. Mfold web server for nucleic acid folding and hybridization prediction. Nucleic Acids Res 31: 3406-3415. 

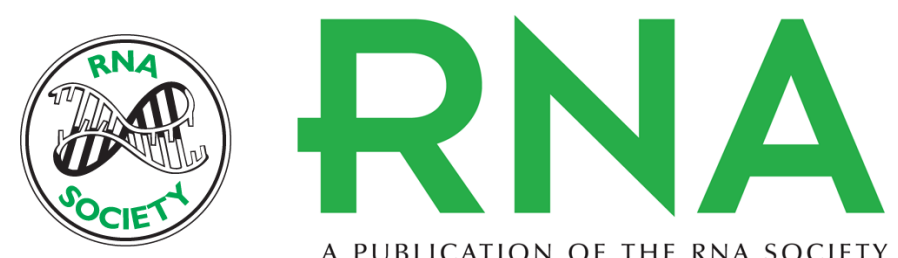

A PUBLICATION OF THE RNA SOCIETY

\title{
Ribosomal RNA processing in Candida albicans
}

\author{
Michael L. Pendrak and David D. Roberts
}

RNA 2011 17: 2235-2248 originally published online October 25, 2011

Access the most recent version at doi:10.1261/rna.028050.111

\section{References}

This article cites 51 articles, 15 of which can be accessed free at:

http://rnajournal.cshlp.org/content/17/12/2235.full.html\#ref-list-1

\section{License}
Email Alerting Receive free email alerts when new articles cite this article - sign up in the box at the Service top right corner of the article or click here.

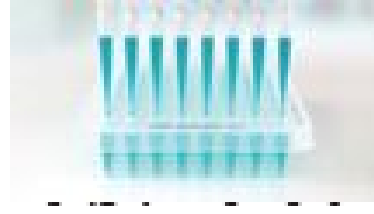

Providing Precise Solutions for your research. 